\title{
Effect of Extrusion Temperature on the Microstructure and Mechanical Properties of SiCnw/2024Al Composite
}

\author{
Shanliang Dong ${ }^{1}$, Bin Zhang ${ }^{2}$, Yuli Zhan ${ }^{2}$, Xin Liu ${ }^{2}$, Ling Xin ${ }^{1, *},{ }^{\dagger}$, Wenshu Yang ${ }^{1, *}$ \\ and Gaohui $\mathrm{Wu}^{1}$ \\ 1 Harbin Institute of Technology, Harbin 150001, China \\ 2 Beijing Institute of Control Engineering, Beijing 100080, China \\ * Correspondence: ling.xin@hit.edu.cn or xinling1732@163.com (L.X.); yws001003@163.com (W.Y.); \\ Tel.: +86-451-86402373-5053 (W.Y.) \\ + Current address: Beijing Institute of Electronic Systems Engineering, Beijing 100854, China.
}

Received: 19 July 2019; Accepted: 27 August 2019; Published: 28 August 2019

\begin{abstract}
In the present research work, the effect of extrusion temperature from 480 to $560{ }^{\circ} \mathrm{C}$ on the microstructure and mechanical behavior of the SiCnw/2024Al composite (15 vol.\%) has been explored. It has been found that extrusion at higher temperature (above $520^{\circ} \mathrm{C}$ ) was beneficial for the densification of the composite, while the residual average length and alignment of the $\mathrm{SiC}$ nanowires were also increased with the extrusion temperature. Moreover, higher extrusion temperature was helpful for the mechanical strength of the SiCnw/2024Al composite, and the peak-aged $\mathrm{SiCnw} / 2024 \mathrm{Al}$ composite extruded at $560^{\circ} \mathrm{C}$ revealed the highest strength $(709.4 \mathrm{MPa})$ and elastic modulus (109.8 GPa).
\end{abstract}

Keywords: metal matrix composites; $\mathrm{Al}$ matrix composite; $\mathrm{SiC}$ nanowires; extrusion temperature; alignment; strengthening

\section{Introduction}

Recently, composites materials reinforced with nano-phases, such as ceramic nano-particles [1,2], carbonous nano-phase (CNT) [3,4] and graphene [5,6] have been widely explored. Besides the above phases, $\mathrm{SiC}$ nanowires are also very promising to be used as reinforcement materials $[7,8]$. It has been reported that the $\mathrm{SiC}$ nanowires could enhance the strength and toughness of polymer [9] and ceramic matrix composites [10].

Utilization of the $\mathrm{SiC}$ nanowires to reinforce metal matrix composites has also been reported. Pozuelo et al. [11] found that the $\mathrm{SiC}$ nanowires could be well bonded with $\mathrm{Mg}$ matrix and suggested that the enhanced interlocking effect between $\mathrm{SiC}$ nanowires and $\mathrm{Mg}$ matrix would be helpful for the mechanical properties. Lee et al. [12] reported that the $\mathrm{SiC}$ nanowires reacted with tungsten matrix to form rod-type $\mathrm{W}_{5} \mathrm{Si}_{3}$ phases, which improved the flexural strength and ablation resistance. Kang et al. [13] also concluded that the $\mathrm{SiC}$ nanowires would react with $\mathrm{W}$ matrix to form $\mathrm{W}_{2} \mathrm{C}$ and $\mathrm{W}_{5} \mathrm{Si}_{3}$, which improved the compressive strength (from 0.9 to $2.29 \mathrm{GPa}$ ) and strain simultaneously. Jintakosol et al. [14] found that the $\mathrm{SiC}$ nanowires could increase the wear resistance of the Al matrix composites significantly. Recently, our research group reported that the microstructure and mechanical behavior of $\mathrm{SiC}$ nanowires reinforced pure $\mathrm{Al}$ and 6061 Al matrix composites [15-20]. Compared with the carbonaceous materials (CNT, graphene), which easily react with $\mathrm{Al}$ matrix to form detrimental $\mathrm{Al}_{4} \mathrm{C}_{3}$ phase [3,21,22], $\mathrm{SiC}$ nanowires-Al interface demonstrated good interfacial bonding performance without $[18,20]$ or with minimal interfacial products [19]. Moreover, it has been found that $15 \mathrm{vol} \%$ 
SiCnw/6061Al composite showed high bending strength (over $1000 \mathrm{MPa}$ ) and comparable plasticity as that of Al matrix [15].

Hot-extrusion treatment has been widely used as an important preparation and strengthening method [23-25]. In our previous work, it has been reported that the mechanical properties of the $\mathrm{SiCnw} / 6061 \mathrm{Al}$ composites could be enhanced by the extrusion treatment regardless of $\mathrm{SiC}$ nanowires content [26]. Usually, the extrusion effect was affected by the parameters (extrusion temperature and ratio) and the characters of the composites (aspect ratio and content of the reinforcement). Luan et al. [27] found that the extrusion temperature $\left(445\right.$ to $570{ }^{\circ} \mathrm{C}$ for $\mathrm{Al}_{2} \mathrm{O}_{3} \mathrm{p} / 2024 \mathrm{Al}$ and 445 to $570{ }^{\circ} \mathrm{C}$ for $\mathrm{Al}_{2} \mathrm{O}_{3} \mathrm{p} / 6061 \mathrm{Al}$ ) showed slight effect on the mechanical properties of $\mathrm{Al}_{2} \mathrm{O}_{3} \mathrm{p} / \mathrm{Al}$ composites. However, Tavighi et al. [28] reported that the tensile strength of the $16 \mathrm{wt} . \% \mathrm{Al}_{4} \mathrm{Srp} / \mathrm{Al}$ composites was decreased with the extrusion temperature $\left(390\right.$ to $\left.500{ }^{\circ} \mathrm{C}\right)$ while the ductility reached maximum at $420^{\circ} \mathrm{C}$. Contrarily, Feng et al. [29] reported that the strength of pure $\mathrm{Al}$ matrix composites reinforced with 22 vol. $\% \mathrm{Al}_{18} \mathrm{~B}_{4} \mathrm{O}_{33}$ whiskers and 3 vol. $\% \mathrm{WO}_{3}$ particles was initially increased and then decreased with the extrusion temperature $\left(440\right.$ to $\left.560^{\circ} \mathrm{C}\right)$. Feng et al. [29] also observed that the length of $\mathrm{Al}_{18} \mathrm{~B}_{4} \mathrm{O}_{33}$ whiskers in the composites was increased with the temperature. Meanwhile, Hong et al. [30] revealed that the strength of $2024 \mathrm{Al}$ composites reinforced with $20 \mathrm{vol} \% \mathrm{SiC}$ whiskers were increased linearly with the extrusion temperature $\left(470\right.$ to $\left.530^{\circ} \mathrm{C}\right)$ due to the improved alignment of the $\mathrm{SiC}$ whiskers. However, the effect of the extrusion temperature on the SiCnw/Al composite, with high strength and high aspect ratio reinforcement (more than 50 ), has not been explored yet.

In the present research work, $15 \mathrm{vol} . \% \mathrm{SiCnw} / 2024 \mathrm{Al}$ composite has been hot-extruded in the temperature range from 480 to $560^{\circ} \mathrm{C}$, and the effect of the extrusion temperature on the microstructure and mechanical behavior of the $\mathrm{SiCnw} / 2024 \mathrm{Al}$ composite has been discussed.

\section{Experimental Design, Materials and Methods}

\subsection{Materials and Composite Fabrication Process}

The raw $\mathrm{SiC}$ nanowire used in the present research was provided by Changsha Sinet Advanced Materials Co., Ltd. Changsha, China, while the 2024Al alloy was supplied by Northeast Light Alloy Co., Ltd. Harbin, China. The chemical composition (wt.\%) of the $2024 \mathrm{Al}$ alloy was $4.23 \% \mathrm{Cu}, 1.58 \% \mathrm{Mg}$, $0.75 \% \mathrm{Mn}, 0.25 \% \mathrm{Zn}, 0.10 \% \mathrm{Cr}$ and $\mathrm{Al}$ balance. The fabrication process of SiCnw/2024Al composite was similar to that of the SiCnw/6061Al composite $[15,18]$, as shown in Figure 1. The preheating temperatures for the preform and graphite indenter were 520 and $760{ }^{\circ} \mathrm{C}$, and the melting temperature of the 2024Al alloy was $840^{\circ} \mathrm{C}$, respectively. Afterwards, the $\mathrm{SiCnw} / 2024 \mathrm{Al}$ billets were hot extruded at $480,500,520$ and $560^{\circ} \mathrm{C}$, respectively. The extrusion ratio and speed were $11: 1$ and $1 \mathrm{~mm} / \mathrm{s}$ respectively. Before mechanical test, the SiCnw/2024Al specimens were treated by peak-aging $\left(495^{\circ} \mathrm{C} / 1 \mathrm{~h}\right.$ solid solution, water quenched and then $160^{\circ} \mathrm{C} / 8 \mathrm{~h}$ aging $)$ or annealing treatment $\left(340^{\circ} \mathrm{C} / 1 \mathrm{~h}\right)$.

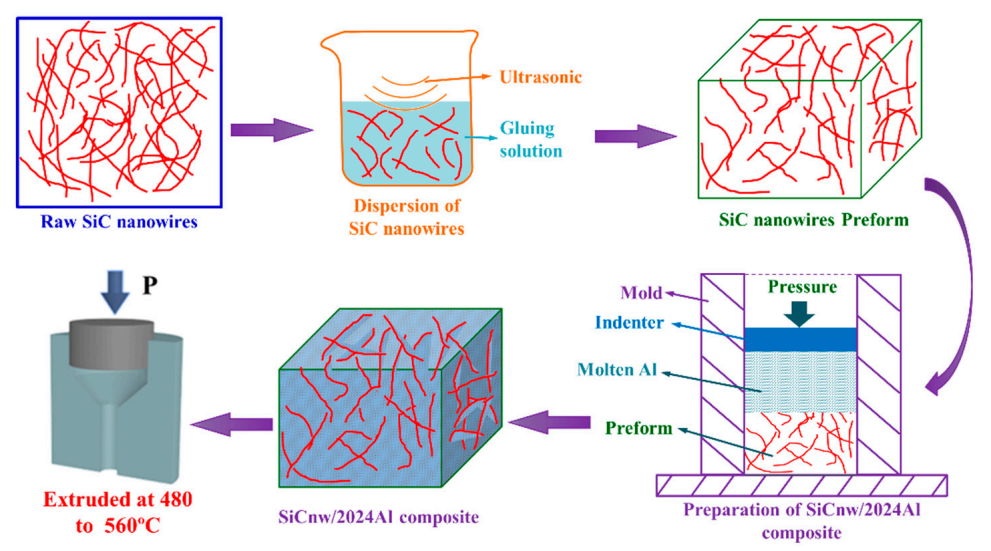

Figure 1. The schematic diagram of preparation and extrusion process of SiCnw/2024Al composite. 


\subsection{Microstructure Characterization}

Microstructure of SiCnw/2024Al specimens were observed by optical microscope (Axiovert 40 MAT, Carl Zeiss, Jena, Germany), scanning electron microscope (SEM) (FEI Sirion Quanta 200, Philips, Amsterdam, Netherlands) and transmission electron microscope (TEM) (JEM-2010F, JEOL, Tokyo, Japan). Energy Dispersive X-Ray (EDX) Spectroscopy equipped in SEM has been applied to detect the distribution of $\mathrm{Al}, \mathrm{Si}$, and $\mathrm{C}$ elements, which was further used to reveal the distribution of $\mathrm{SiC}$ nanowires. The density of all samples $(10 \mathrm{~mm} \times 10 \mathrm{~mm} \times 2 \mathrm{~mm})$ was measured using Archimedes principle, and four samples have been tested to improve the statistical significance of the results. The relative density of the composites before and after extrusion was calculated by comparison of the measured true density and the "theoretical" density of the samples extruded at $560^{\circ} \mathrm{C}$. X-ray diffraction (XRD) was performed on Rigaku D/max-rB diffractometer with $\mathrm{Cu}-\mathrm{K} \alpha$ radiation $(0.15418 \mathrm{~nm})$ between $15^{\circ}$ and $90^{\circ}$.

\subsection{Mechanical Properties Testing}

Elastic modulus was tested by impulse excitation of vibration on samples with dimensions of $3 \mathrm{~mm} \times 4 \mathrm{~mm} \times 36 \mathrm{~mm}$ according to ASTM E 1876 (EMT-01, Zhuosheng Instrument Co., Ltd. Luoyang, China). Parallel to the extrusion direction, tensile properties were measured on universal electrical tensile testing machine (Instron 5569, Instron Co., Norwood, MA, USA) with a speed of $0.5 \mathrm{~mm} / \mathrm{min}$, and eventually the SEM fracture surface was observed by Quanta 200. The tensile samples $(2 \mathrm{~mm}$ in thickness) were prepared from the composites, as shown in Figure 2. Six samples extruded at different temperature were tested for each set of composite samples to improve the statistical significance of the results.

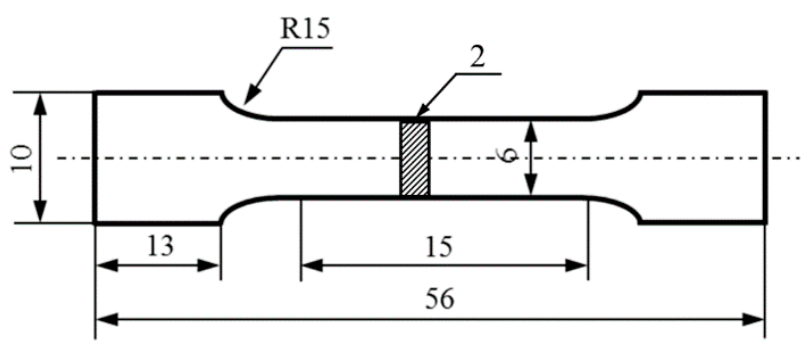

Figure 2. Dimensions of tensile test samples (2 $\mathrm{mm}$ in thickness).

\section{Results and Discussion}

\subsection{Effect of Extrusion Temperature on the Microstructure of SiCnw/2024Al Composite}

Due to the large difference between the size of the $\mathrm{SiC}$ nanowires (about sub-micron) and pores (about $20 \mu \mathrm{m}$ ), it is difficult to show them both clearly in the same image. In order to show the effect of the extrusion treatment on the distribution of pores in the composites, optical morphologies of $\mathrm{SiCnw} / 2024 \mathrm{Al}$ composite extruded at different temperature have been shown in Figure 3. Several pores, which have been marked out by the dashed circles, were found in the as-casted SiCnw/2024Al composite (Figure 3a). It was mainly due to the relatively poor wettability between $\mathrm{SiC}$ and $\mathrm{Al}$ matrix [31]. Zeng et al [32] reported that the increased sintering temperature was beneficial for the densification of $\mathrm{Si}_{3} \mathrm{~N}_{4} \mathrm{w} / \mathrm{Al}$ composites. Meanwhile, Zeng et al. [33] found innovatively that the Ag surface modification of the $\mathrm{Si}_{3} \mathrm{~N}_{4}$ whiskers could improve the relative density of the $\mathrm{Si}_{3} \mathrm{~N}_{4} \mathrm{w} / \mathrm{Al}$ composite, and Zeng et al. [33] attributed the effect to the lower eutectic point of Al-Ag interface, improved wetting behavior, and broken down of the $\mathrm{Al}_{2} \mathrm{O}_{3}$. These interesting results would be referable for further improving of the densification result. After extrusion treatment, the porosity of the $\mathrm{SiCnw} / 2024 \mathrm{Al}$ composite has been significantly decreased (Figure $3 \mathrm{~b}, \mathrm{c}$ ). It has been widely reported that one of the main advantages of the hot-extrusion treatment is the densification $[23,25,29]$. Moreover, the porosity of the $\mathrm{SiCnw} / 2024 \mathrm{Al}$ composite has been almost eliminated after extrusion treatment at 
$520{ }^{\circ} \mathrm{C}$ and $560{ }^{\circ} \mathrm{C}$ (Figure $3 \mathrm{~d}$,e), indicating more effective densification process at higher temperatures due to the good deformability of the $\mathrm{Al}$ matrix [30].

After extrusion, the measured density of the composites was initially increased with and eventually stabilized above $520^{\circ} \mathrm{C}$ with the increase of the extrusion temperature, indicating that the composites have reached full densification after extrusion at $560{ }^{\circ} \mathrm{C}$. Therefore, the measured true density of the composites in various states were divided to the "theoretical" density of the samples extruded at $560{ }^{\circ} \mathrm{C}$, and then the relative density has been obtained, as shown in Figure 4 . It is clear that the composites have been densified after the extrusion, and the densification effect was also improved with the extrusion temperature, which agreed well with optical microstructure observation (Figure 2).

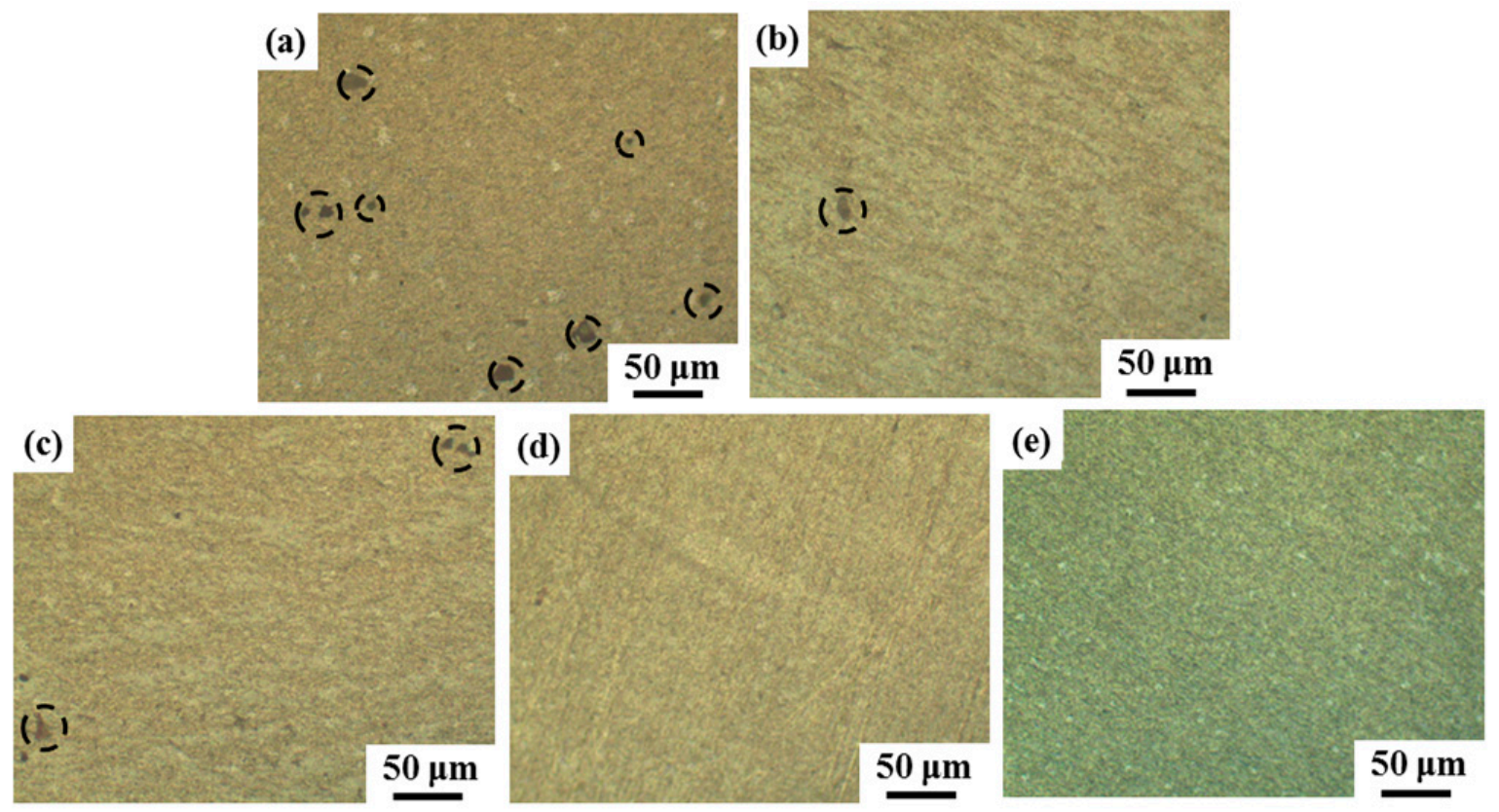

Figure 3. Representative optical morphologies of $\mathrm{SiCnw} / 2024 \mathrm{Al}$ composite (a) before extrusion and extruded at (b) $480{ }^{\circ} \mathrm{C}$, (c) $500{ }^{\circ} \mathrm{C}$, (d) $520^{\circ} \mathrm{C}$ and (e) $560{ }^{\circ} \mathrm{C}$.

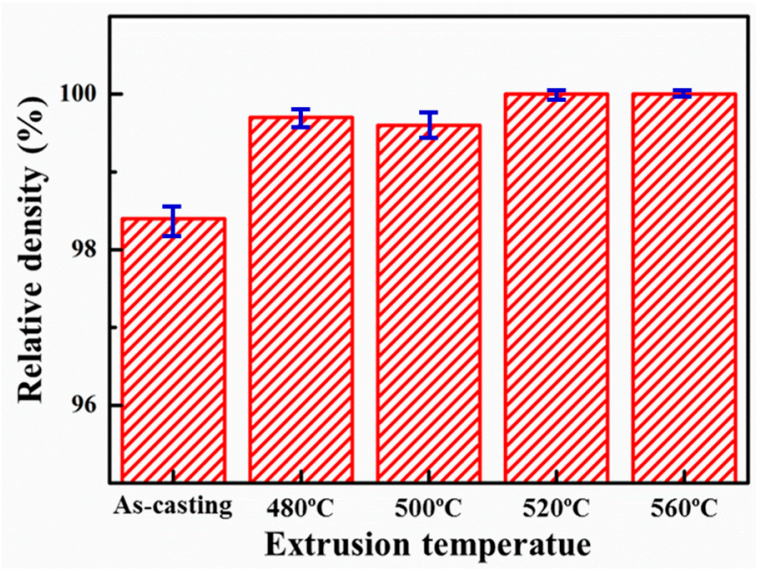

Figure 4. Effect of extrusion temperature on the relative density of the SiCnw/2024Al composite.

In order to reveal the distribution of the $\mathrm{SiC}$ nanowires in the composites, EDX mapping has been performed, and the distribution of the $\mathrm{Al}, \mathrm{Si}$ and $\mathrm{C}$ elements have been shown in Figure 5. Due to the accuracy of the EDX, the distribution of $C$ element was not very reliable. However, the distribution of Si element was very clear, as shown in Figure 5c. Due to the low content of Si element in 2024Al matrix, the distribution of $\mathrm{Si}$, mainly in morphology of rod-like structures, could be considered to 
be equivalent to distribution of $\mathrm{SiC}$ nanowires. This is also in agreement with our previous research work [15,17] and literature results [11,14].
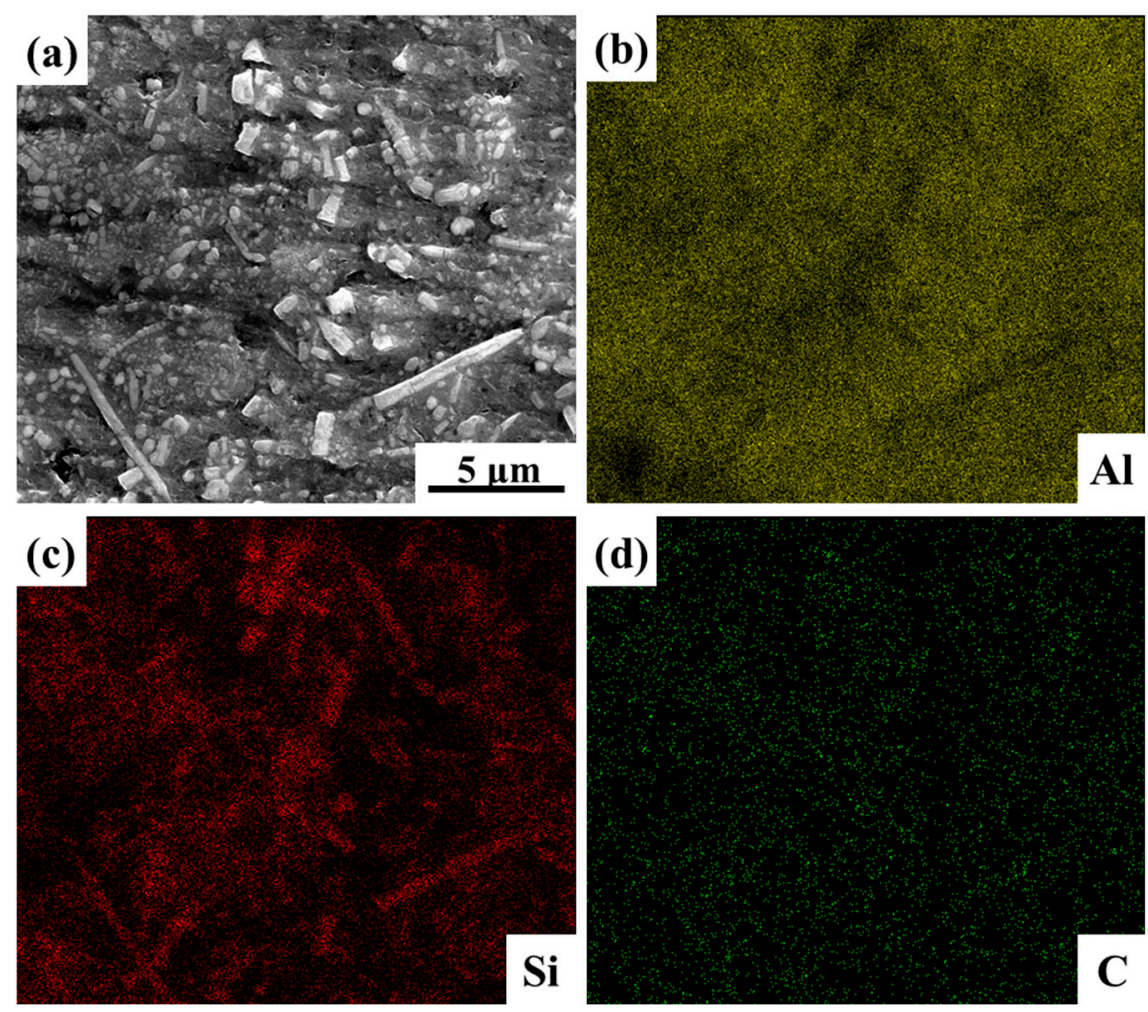

Figure 5. Energy Dispersive X-Ray (EDX) mapping of the polished SiCnw/2024Al composite. (a) SEM image and corresponding distribution of (b) $\mathrm{Al},(\mathbf{c}) \mathrm{Si}$ and (d) C, respectively.

Figure 6 shows the effect of extrusion treatment on the SEM alignments of the SiC nanowires in the composite. In order to observe the $\mathrm{SiC}$ nanowires' distribution clearer, the polished samples were etched by $10 \% \mathrm{NaOH}$ solution for $120 \mathrm{~s}$. Since the results were quite similar regardless of the extrusion temperature, only the $\mathrm{SiC}$ nanowires alignments extruded at $560{ }^{\circ} \mathrm{C}$ (Figure $5 \mathrm{~b}, \mathrm{c}$ ) were exhibited. Before extrusion treatment, $\mathrm{SiC}$ nanowires towards different directions were observed (Figure 6a), indicating their random distribution. However, after extrusion treatment, the well aligned ends of the $\mathrm{SiC}$ nanowires were observed to be perpendicular to the extrusion direction (Figure 6b), while significant orientation of the SiC nanowires along extrusion axis has been found to be parallel to the extrusion direction (Figure 6c), indicating the well alignment of the SiC nanowires along the extrusion direction. Attributed to the rheology shear stress of the Al matrix, the reinforcements are prone to being re-distributed along the extrusion direction. Moreover, it has been widely reported that the extrusion treatment would cause the breakage of high aspect ratio reinforcements (such as whiskers $[29,34])$ due to the mismatch of the deformation ability. In order to measure the average length of the $\mathrm{SiC}$ nanowires after extrusion, the microstructure of SiCnw/2024Al composite extruded at $560{ }^{\circ} \mathrm{C}$ after being etched by $10 \% \mathrm{NaOH}$ solution for $480 \mathrm{~s}$ is shown in Figure $7 \mathrm{a}$, and eventually the length of the $\mathrm{SiC}$ nanowires was counted by the Nano Measurer software. After statistical analysis, the normal distribution of the SiC nanowires' length could be given by the software, as shown in Figure $7 \mathrm{~b}$. The effect of extrusion temperature on the average length of the $\mathrm{SiC}$ nanowires has been shown in Figure 8. Regardless of the extrusion temperature, it is clear that the average length of the $\mathrm{SiC}$ nanowires after the extrusion treatment was about half of that in the as-casted composite (Figure 8), indicating severe breakage of the $\mathrm{SiC}$ nanowires during the extrusion treatment. During the hot extrusion process, the Al matrix could be deformed plastically while the SiC nanowires were considered as non-deformable phases, which would be rotated due to the rheological stress of the $\mathrm{Al}$ 
matrix, and then the breakage of the SiC nanowires could occur. For the reinforcement with large size (such as $\mathrm{Al}_{4} \mathrm{Sr}$ phase with about $30 \mu \mathrm{m}$ in thickness [28]), the areas between the broken phases could not be re-filled fully by the Al matrix, and they would therefore act as crack sources and thus decrease the mechanical properties of the composites. However, for the reinforcement with small size (diameter less than a few microns) [27,29], the areas between the broken reinforcement could be healed by the Al matrix. Thus, the extruded composites would express rather high relative density and high mechanical performance. However, it is worth noting that the average length of the SiC nanowires was increased with the extrusion temperature (Figure 8). This agreed well with the results reported by Feng et al. [29] and Hong et al. [30]. It was mainly due to the decreased deformation resistance of the $\mathrm{Al}$ matrix on the rotation of the $\mathrm{SiC}$ nanowires at higher extrusion temperature [30].

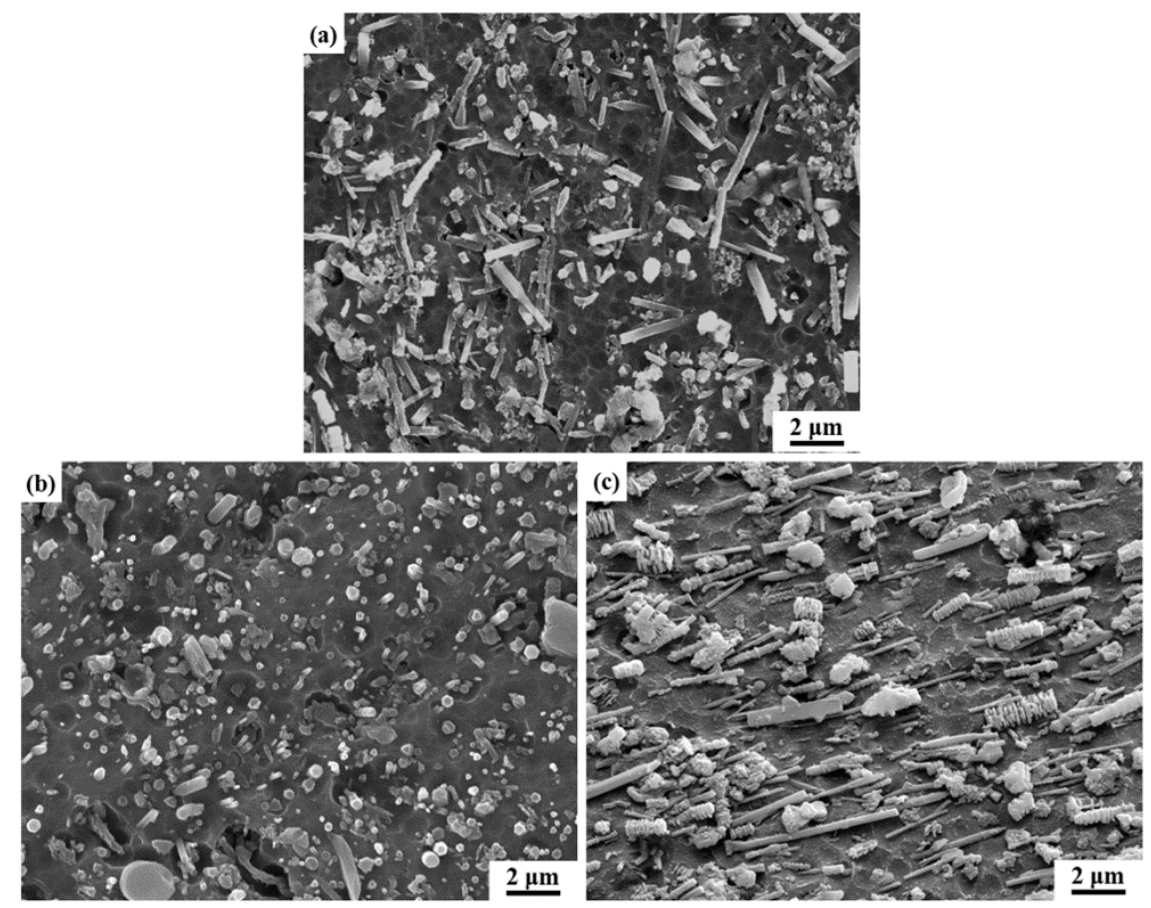

Figure 6. The representative SEM microstructure of the SiCnw/2024Al composite (a) before and after $560^{\circ} \mathrm{C}$ extrusion observed in the direction (b) perpendicular and (c) parallel to the extrusion direction.
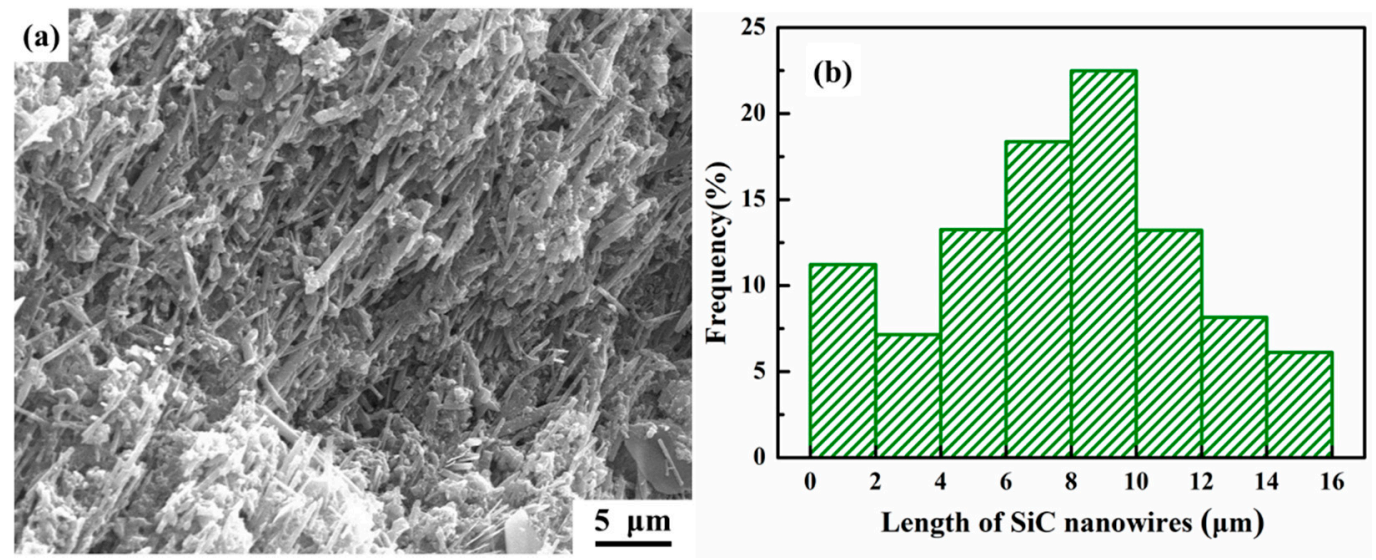

Figure 7. Microstructure of $\mathrm{SiCnw} / 2024 \mathrm{Al}$ composite extruded at $560^{\circ} \mathrm{C}$ after being etched by $10 \% \mathrm{NaOH}$ solution for $480 \mathrm{~s}$ and corresponding statistical results of the $\mathrm{SiC}$ nanowires' length. (a) Microstructure, (b) Statistical results. 


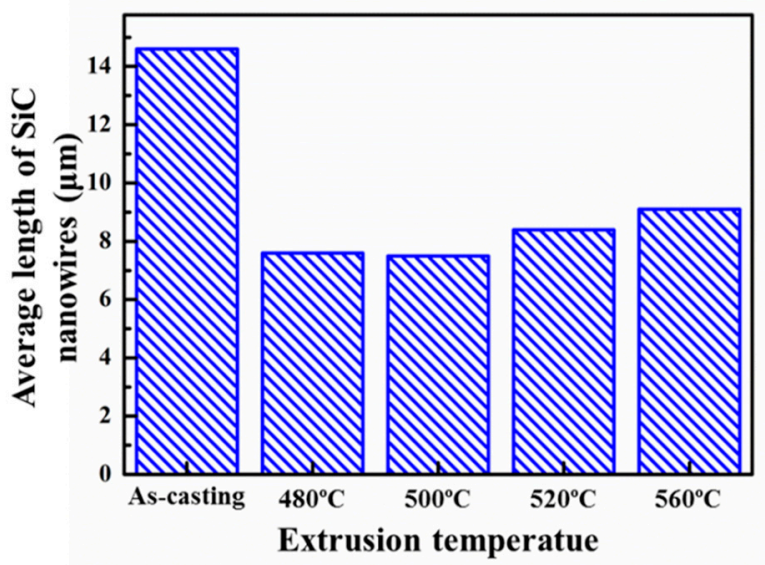

Figure 8. The effect of extrusion temperature on the average length of the $\mathrm{SiC}$ nanowires in the SiCnw/2024Al composite.

The XRD patterns of the extruded SiCnw/2024Al composite, whose analyzed surface was perpendicular and parallel to the extrusion direction, have been shown in Figures 9 and 10, respectively. Regardless of the testing direction, only diffraction peaks of $\mathrm{SiC}$ and $\mathrm{Al}$ were detected (Figures 9a and 10a). The corresponding diffraction peaks of the (111) and (220) planes of the SiC nanowires have been shown in Figures 9b/10b and 9c/Figure 10c, respectively. The peak value ratio (PVR) of the XRD patterns of the (111) and (220) planes of the $\mathrm{SiC}$ nanowires were calculated as:

$$
\operatorname{PVR}=\frac{I_{(111)}}{I_{(220)}}
$$

where $I$ is the peak value of the XRD pattern, the subscript (111) and (220) represent the (111) and (220) planes, respectively.
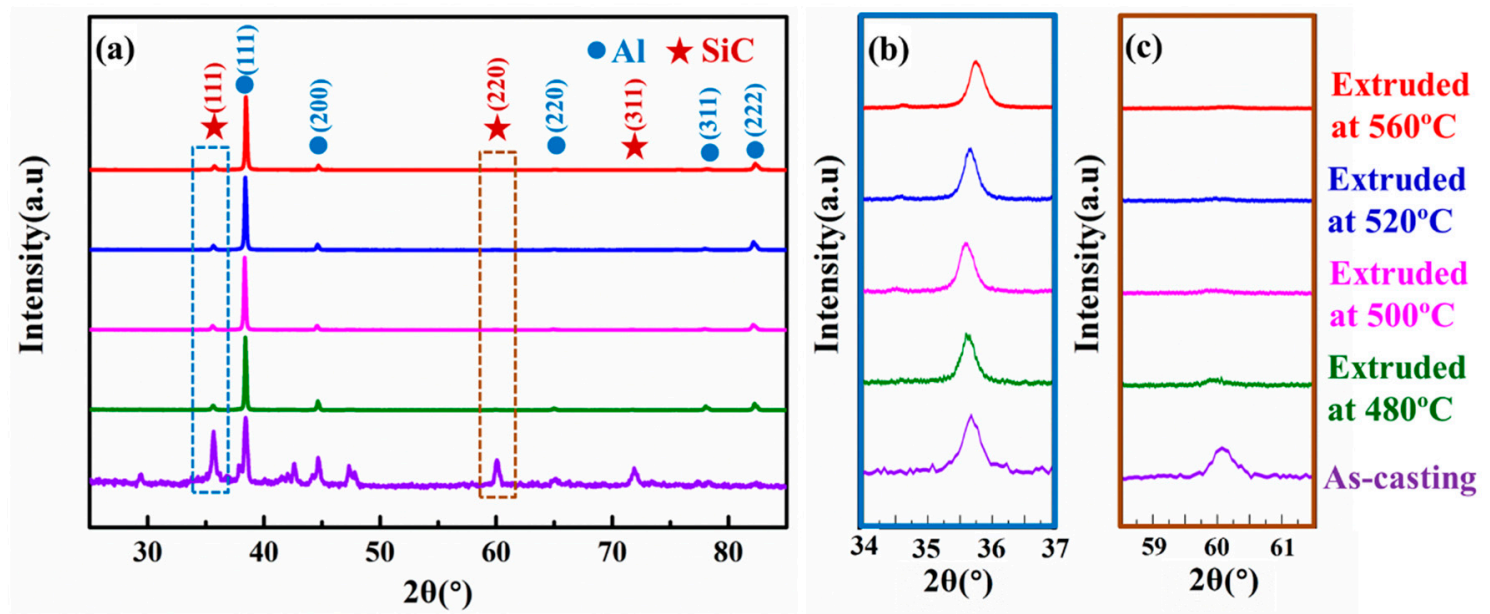

Figure 9. The XRD patterns of the SiCnw/2024Al composite before and after extrusion treatment on the surface perpendicular to the extrusion direction. (a) Overall patterns and the high magnification of the (b) (111) planes and (c) (220) of the $\mathrm{SiC}$ phase. 

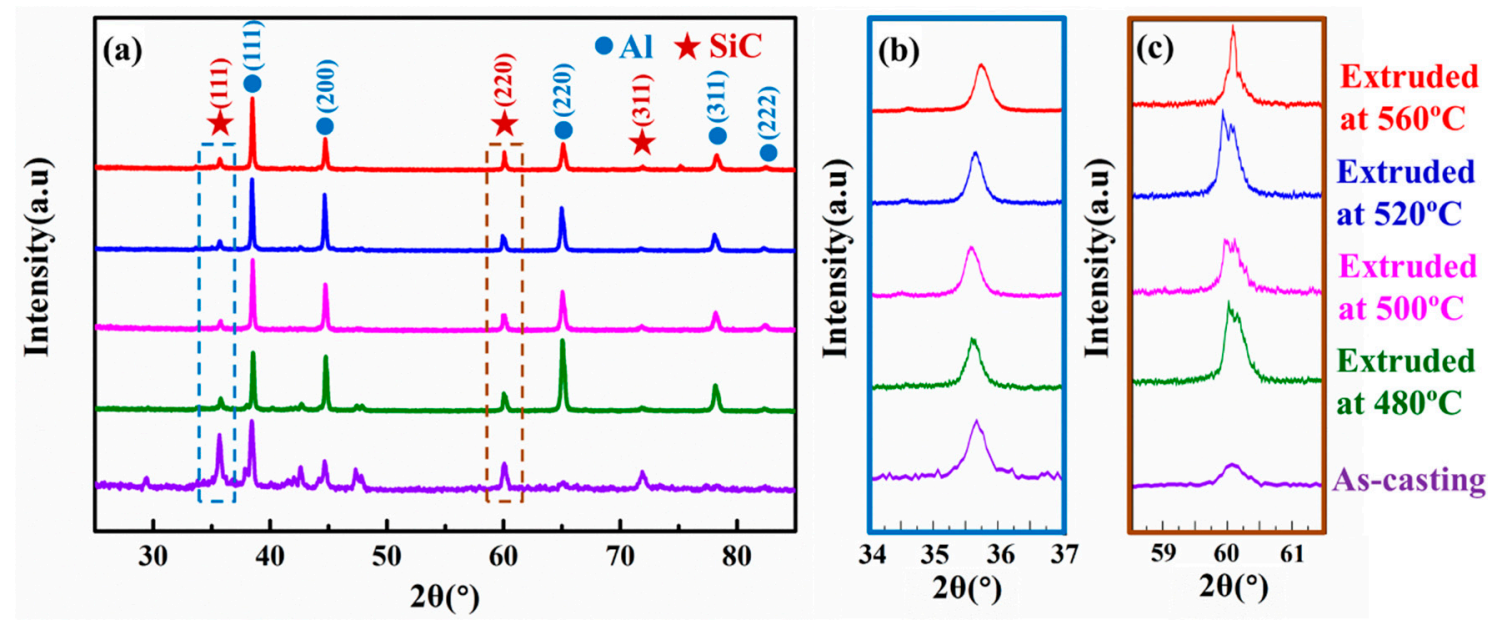

Figure 10. The XRD patterns of the SiCnw/2024Al composite before and after extrusion treatment on the surface parallel to the extrusion direction. (a) Overall patterns and the high magnification of the (b) (111) planes and (c) (220) of the SiC phase.

The PVR of the $\mathrm{SiC}$ nanowires in the SiCnw/2024Al composite in perpendicular and parallel to the extrusion direction has been shown in Figure 11. In the perpendicular direction, the PVR of the $\mathrm{SiC}$ nanowires was increased with the extrusion temperature, indicating the increased diffraction intensity of the (111) planes. However, in the parallel extrusion, the PVR of the SiC nanowires was decreased with the extrusion temperature, indicating the increased diffraction intensity of the (220) planes [111] axes is the axial direction of the $\mathrm{SiC}$ nanowires, while the (111) planes are the stacking planes of the 3C-SiC $[35,36]$. The increased PVR in the perpendicular direction and the decreased PVR in the parallel direction indicated the increased alignment degree of the SiC nanowires along the extrusion direction. Therefore, alignment degree of the $\mathrm{SiC}$ nanowires was increased with the extrusion temperature, which is consistent with the results reported by Feng et al. [29] and Hong et al. [30].

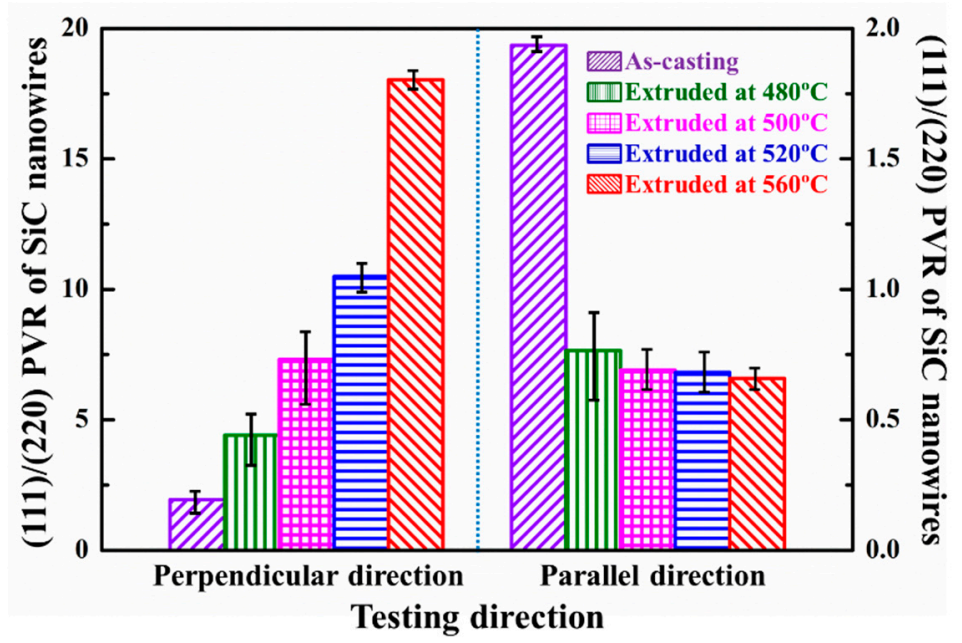

Figure 11. The (111)/(220) peak value ratio (PVR) of the SiC nanowires in the SiCnw/2024Al composite in perpendicular and parallel to the extrusion direction.

The microstructure of extruded SiCnw/2024Al composite after annealing has been further observed by TEM, as shown in Figure 12. The $\mathrm{SiC}$ nanowires, as marked out by arrow in Figure 12a, were mainly perpendicular to the observation direction. The selected area electron diffraction (SAED) patterns of the dark phase (as marked out by yellow dashed circle) have been shown in Figure 12b. It is clear that two set patterns could be found, while the central spots and the second hexagonal spots of the SAED of the $\mathrm{SiC}$ nanowires were very bright, and the first hexagonal spots were relatively dark (Figure 12b). In our 
previous research work [37], the cross-section and axial microstructure of the SiC nanowires embedding into $\mathrm{Al}$ matrix have been investigated, and it has been found that the $\mathrm{SiC}$ nanowires were composed of a large number of small fragments that are formed by hybrid $3 \mathrm{C}-\mathrm{SiC}$ and $2 \mathrm{H}-\mathrm{SiC}$ structures. Therefore, their SAED patterns were composed of two sets of diffraction patterns, corresponding to $2 \mathrm{H}-\mathrm{SiC}$ and $3 \mathrm{C}-\mathrm{SiC}$, respectively, which agreed well with the present observation. Moreover, high magnification image indicated that the presence of the $\mathrm{SiC}$ nanowires was mainly located at the boundary of $\mathrm{Al}$ grains, as shown in Figure 12c. Usually, for SiCnw/Al composites prepared by pressure infiltration method, the SiC nanowires were mainly located within the Al grains due to the solidification of the matrix $[15,20]$. It is suggested that the "non-deformable" $\mathrm{SiC}$ nanowires inhabited the movement and deformation of surrounding Al matrix, leading to the formation of the grain boundaries [26,29]. The refinement of the Al matrix grain would also be beneficial for the mechanical properties. However, a few non-directional $\mathrm{SiC}$ nanowires could have also been observed in the composites, as shown in Figure 12d.
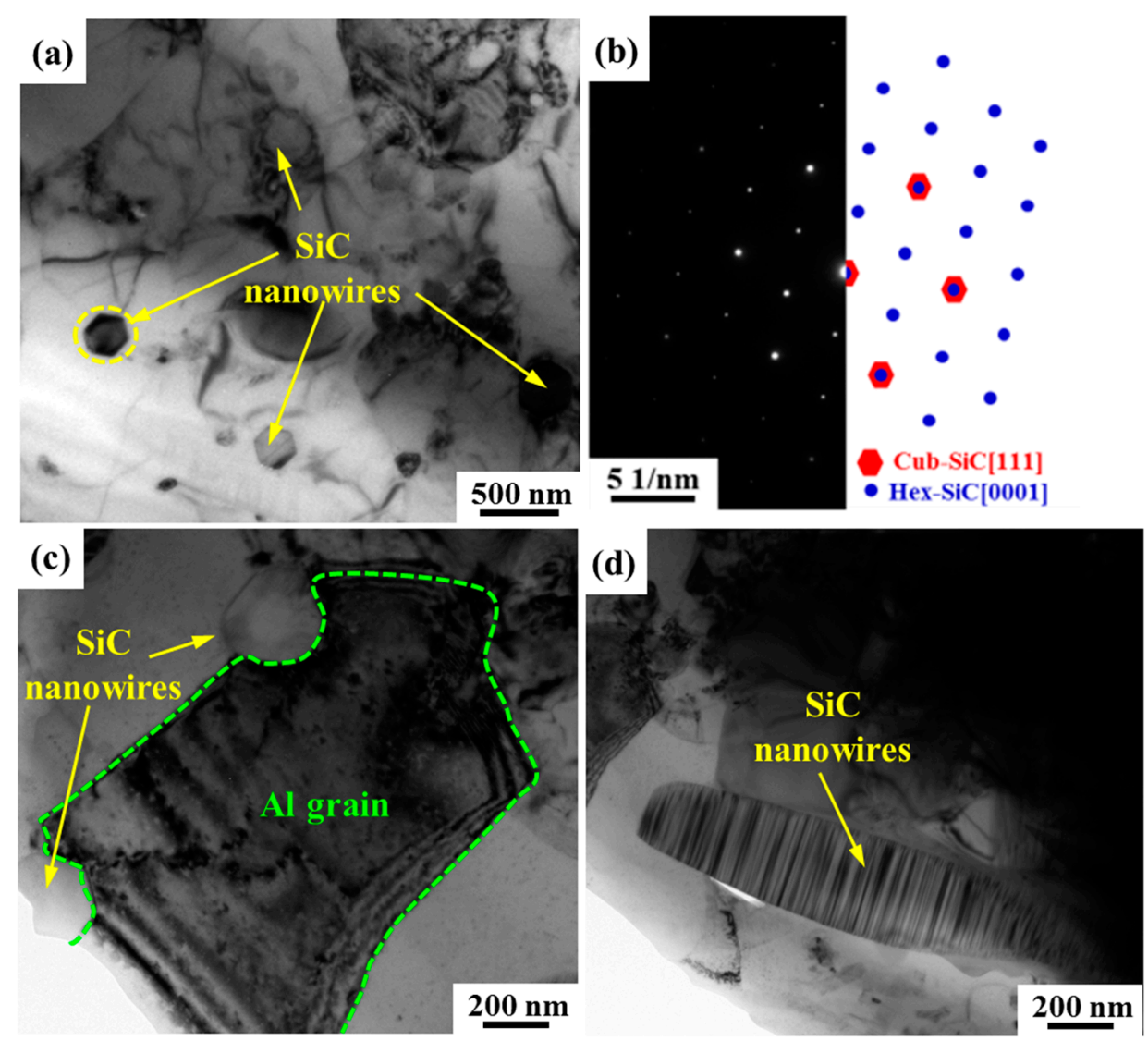

Figure 12. The TEM microstructure of extruded SiCnw/2024Al composite after annealing. (a) Low magnification image, (b) selected area electron diffraction (SAED) patterns of the SiC nanowire in the dashed circle and (c) $\mathrm{SiC}$ nanowires located at the boundaries of Al grains, (d) few non-directional $\mathrm{SiC}$ nanowires.

\subsection{Effect of Extrusion Temperature on the Mechanical Behavior of SiCnw/2024Al Composite}

The representative tensile curves of annealed and peak-aged SiCnw/2024Al composite extruded at different temperature have been shown in Figure 13. The annealed SiCnw/2024Al composite showed very low plastic deformation while the peak-aged SiCnw/2024Al composite showed the typical characters of the brittle fracture. The detailed comparison of the yield and tensile strength has been shown in Figure 14. Since the peak-aged SiCnw/2024Al composite was fractured before yield deformation, its yield strength has not been obtained. Regardless of the heat treatment, the yield 
and tensile strengths of the $\mathrm{SiCnw} / 2024 \mathrm{Al}$ composite were increased with the extrusion temperature. Moreover, the peak-aged SiCnw/2024Al composite showed higher tensile strength, which should be attributed to the strengthening effect of the precipitates. Fracture surface of SiCnw/2024Al composite extruded at $560{ }^{\circ} \mathrm{C}$ has been shown in Figure 15. Many dimples and tearing ridges were observed in the fracture surface (Figure 15a), indicating severe deformation of $\mathrm{Al}$ matrix. Moreover, several broken and pull-out SiC nanowires, which have been pointed out by yellow arrows in Figure 15b, were also observed. Meanwhile, the elastic moduli of the SiCnw/2024Al composite before and after the extrusion treatment were 101.3 and $109.8 \mathrm{GPa}$, respectively. However, for the composites after extrusion, the extrusion temperature showed minimal effect on the elastic modulus of the SiCnw/2024Al composite. The increased elastic modulus was mainly due to the improved relative density [26,38]. Regardless of the extrusion temperature, the $\mathrm{SiCnw} / 2024 \mathrm{Al}$ composite after extrusion treatment could be considered to be fully densified (Figure 4), leading to the slight variation of the elastic modulus at different extrusion temperature. The peak-aged SiCnw/2024Al composite showed high strength (709.4 MPa) and elastic modulus (109.8 GPa), which are very attractive features for aerospace application.
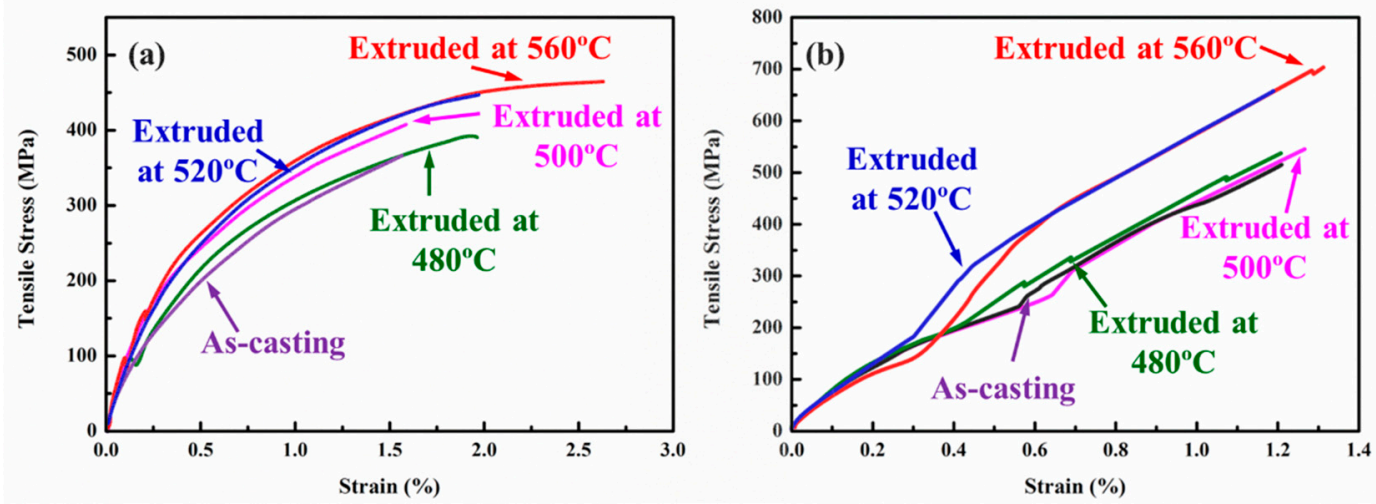

Figure 13. The representative tensile curves of (a) annealed and (b) peak-aged SiCnw/2024Al composite extruded at different temperature.

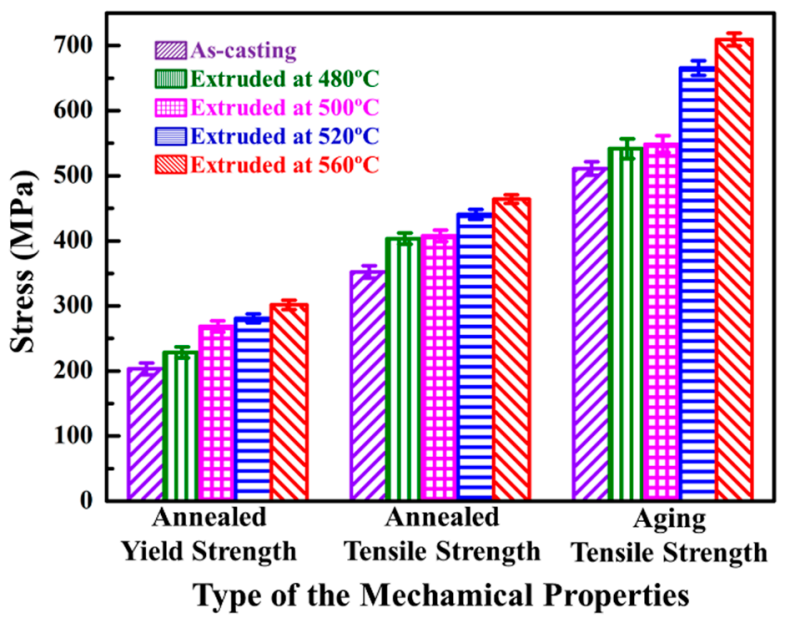

Figure 14. The detailed comparison of the yield and tensile strength of the SiCnw/2024Al composite. 

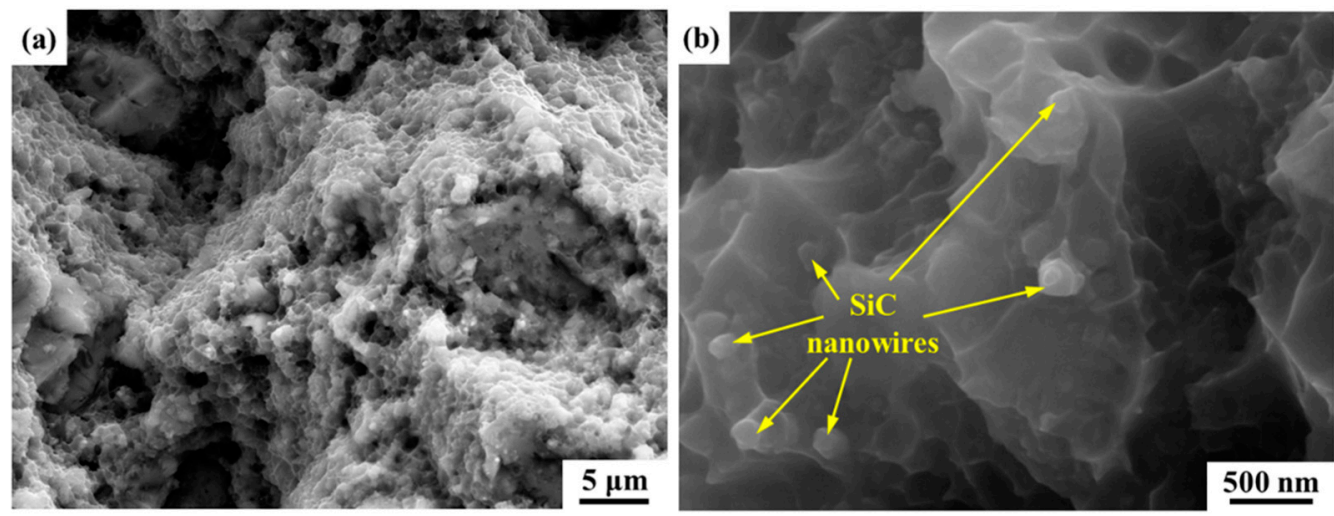

Figure 15. Fracture surface of $\mathrm{SiCnw} / 2024 \mathrm{Al}$ composite extruded at $560{ }^{\circ} \mathrm{C}$.

The strength of discontinuous phases reinforce metal matrix composites could be well explained by the modified shear-lag model after taking into account the tensile transfer of the load from the matrix to the discontinuous reinforcement $[23,39]$. Moreover, it has been suggested that the strengthening behavior of the SiCnw/Al composites could be well described by the modified shear-lag model which considers the effect of the aspect ratio of reinforcements $(l / 2 r)$, reinforcement-matrix interfacial bonding properties $k$, the surface-to-volume ratio of the reinforcement (the geometry factor, $g$ ) and the average angle between the loading direction and the reinforcement axis (the alignment factor, $\psi$ ) $[20,26,40]$. If the length of the $\mathrm{SiC}$ nanowires $(l)$ is longer than the critical length $\left(l_{c}\right)$, then the strengthening behavior of the $\mathrm{SiCnw} / \mathrm{Al}$ composites could be written as:

$$
\sigma_{c}=\sigma_{m}+c k g \psi \frac{l}{2 r}\left(2-\frac{l_{c}}{l}\right) \tau_{\max } V_{r}
$$

where $\sigma_{c}$ and $\sigma_{m}$ are the strengths of the composite and matrix, $V_{r}$ is the volume amount of reinforcement, $c$ is an empirical constant for the correction, $r$ is radius of the reinforcements, $\tau_{\max }$ is maximum shear stress, respectively.

Due to comprehensive effect of the helpful aspects (decreased porosity, increased alignment) and detrimental aspect (decreased average length), the strength of the SiCnw/2024Al composite has been improved after the extrusion treatment. For the well densified $\mathrm{SiCnw} / 2024 \mathrm{Al}$ composite after extrusion, the $\sigma_{m}, r, k, g, l_{c}, V_{r}$ and $\tau_{\max }$ could be considered as the same parameters. Moreover, the constant $c$ might be solely dependent on the bonding properties of reinforcement elements [40]. Therefore, the strength of the composites after extrusion was mainly affected by the alignment factor $\psi$ and the length of the $\mathrm{SiC}$ nanowires $l$. Since the alignment (Figure 11) and the average length (Figure 7) of the $\mathrm{SiC}$ nanowires were increased, the strength of the $\mathrm{SiCnw} / 2024 \mathrm{Al}$ composite was increased with the extrusion temperature. It should be noted that the peak-aged $\mathrm{SiCnw} / 2024 \mathrm{Al}$ composite was failure before yield deformation $(0.2 \%)$ and the yield strength of the SiCnw/2024Al composite has the potential to be more than $700 \mathrm{MPa}$, optimistically, if the composites demonstrated certain plasticity. Therefore, the main challenge for $\mathrm{SiCnw} / \mathrm{Al}$ composites to achieve high strength is to improve the ductility.

\section{Conclusions}

In the present work, the effect of extrusion temperature from 480 to $560{ }^{\circ} \mathrm{C}$ on the microstructure and mechanical behavior of the $15 \mathrm{vol} . \% \mathrm{SiCnw} / 2024 \mathrm{Al}$ composite prepared by pressure infiltration methods have been investigated, and following conclusions have been obtained:

1. After extrusion treatment, the porosity of the SiCnw/2024Al composite has been significantly decreased, and the composites have reached full densification after extrusion at $560^{\circ} \mathrm{C}$. Moreover, the average length of the residual $\mathrm{SiC}$ nanowires was also increased with the extrusion temperature. 
2. The distribution of the SiC nanowires has been changed from random to alignment along the extrusion direction, while the alignment degree of the $\mathrm{SiC}$ nanowires was increased with the extrusion temperature according to XRD analysis. TEM observation indicated that the presence of the $\mathrm{SiC}$ nanowires was mainly located at the boundary of $\mathrm{Al}$ grains due to their "non-deformable" character.

3. Regardless of the heat treatment, the yield and tensile strengths of the SiCnw/2024Al composite were increased with the extrusion temperature, and many dimples and tearing ridges were observed in the fracture surface. The peak-aged SiCnw/2024Al composite extruded at $560{ }^{\circ} \mathrm{C}$ revealed highest strength (709.4 $\mathrm{MPa}$ ) and elastic modulus (109.8 GPa).

4. Based on the modified shear-lag mode, the effect of the extrusion temperature on the mechanical properties of the SiCnw/2024Al composite has been discussed, and the improved strength was mainly due to the better alignment and longer average length of the $\mathrm{SiC}$ nanowires at higher extrusion temperature.

Author Contributions: Analysis, writing—original draft preparation, S.D.; Microstructure observation, B.Z.; Heat treatment, Y.Z.; mechanical properties test, X.L.; Conceptualization L.X. and W.Y.; supervision, G.W.

Funding: This research was funded by the National Natural Science Foundation of China (grant numbers 51871073, 51871072, 51771063, 61604086 and U1637201), China Postdoctoral Science Foundation (grant number 2016M590280 and 2017T100240), Heilongjiang Postdoctoral Foundation (grant number LBH-Z16075) and the Fundamental Research Funds for the Central Universities (grant numbers HIT.NSRIF.20161 and HIT. MKSTISP. 201615).

Conflicts of Interest: The authors declare no conflict of interest.

\section{References}

1. Tian, W.-S.; Zhao, Q.-L.; Zhao, C.-J.; Qiu, F.; Jiang, Q.-C. The Dry Sliding Wear Properties of Nano-Sized $\mathrm{TiC}_{\mathrm{p}} / \mathrm{Al}-\mathrm{Cu}$ Composites at Elevated Temperatures. Materials 2017, 10, 939. [CrossRef] [PubMed]

2. Lin, K.; Wang, W.; Jiang, R.; Xiong, Y.; Zhao, D. Evaluation of residual stress distribution and relaxation on in situ TiB2/7050 Al composites. Materials 2018, 11, 706. [CrossRef] [PubMed]

3. Jia, D.; Ma, J.; Gan, X.; Tao, J.; Xie, M.; Yi, J.; Liu, Y. A Comparison Study of Ag Composites Prepared by Spark Plasma Sintering and Hot Pressing with Silver-Coated CNTs as the Reinforcements. Materials 2019, 12, 1949. [CrossRef] [PubMed]

4. Zhao, L.; Yao, P.; Zhou, H.; Gong, T.; Deng, M.; Zhang, Z.; Xiao, Y.; Deng, H.; Li, Y.; Luo, F. Effect of CNTs in Copper Matrix on Mechanical Characteristics and Tribological Behavior under Dry Sliding and Boundary Lubrication Conditions. Materials 2019, 12, 2203. [CrossRef] [PubMed]

5. Yu, Z.; Yang, W.; Zhou, C.; Zhang, N.; Chao, Z.; Liu, H.; Cao, Y.; Sun, Y.; Shao, P.; Wu, G. Effect of ball milling time on graphene nanosheets reinforced Al6063 composite fabricated by pressure infiltration method. Carbon 2019, 141, 25-39. [CrossRef]

6. Lee, H.K.; Talib, Z.A.; Mamat Mat Nazira, M.S.; Wang, E.; Lim, H.N.; Mahdi, M.A.; Ng, E.K.; Yusoff, N.M.; AL-Jumaili, B.E.; Liew, J.Y.C. Effect of Sodium Hydroxide Concentration in Synthesizing Zinc Selenide/Graphene Oxide Composite via Microwave-Assisted Hydrothermal Method. Materials 2019, 12, 2295. [CrossRef] [PubMed]

7. Zhang, L.; Li, S.; Li, H.; Pei, L. Bioactive surface modification of carbon/carbon composites with multilayer $\mathrm{SiC}-\mathrm{SiC}$ nanowire-Si doped hydroxyapatite coating. J. Alloys Compd. 2018, 740, 109-117. [CrossRef]

8. Li, H.; Wang, Y.; Fu, Q.; Chu, Y. SiC Nanowires Toughed HfC Ablative Coating for C/C Composites. J. Mater. Sci. Technol. 2015, 31, 70-76. [CrossRef]

9. Fan, J.; Xu, S. Thermal conductivity and mechanical properties of high density polyethylene composites filled with silicon carbide whiskers modified by cross-linked poly (vinyl alcohol). J. Mater. Sci. Technol. 2018, 34, 2407-2414. [CrossRef]

10. Chu, Y.; Chen, J.; Tang, J. SiC nanowire-induced fabrication of fine-grained and highly-density SiC coating by pressure-less reactive sintering. J. Alloys Compd. 2018, 755, 206-210. [CrossRef]

11. Pozuelo, M.; Kao, W.H.; Yang, J.M. High-resolution TEM characterization of SiC nanowires as reinforcements in a nanocrystalline Mg-matrix. Mater. Charact. 2013, 77, 81-88. [CrossRef] 
12. Lee, D.; Park, H.; Ryu, H.; Jeon, S.; Hong, S. Microstructure and mechanical properties of SiC-nanowire-augmented tungsten composites. J. Alloys Compd. 2011, 509, 9060-9064. [CrossRef]

13. Kang, K.; Zhang, L.; Luo, G.; Zhang, J.; Tu, R.; Wu, C.; Shen, Q. Microstructural evolution and mechanical behavior of W-Si-C multi-phase composite prepared by arc-melting. Mater. Sci. Eng. A 2018, 712, 28-36. [CrossRef]

14. Jintakosol, T.; Kumfu, S.; Singjai, P.; Busabok, C. Effect of wear tests on silicon carbide nanowires/aluminium metal powder composites. Chiang Mai J. Sci. 2012, 39, 41-48.

15. Dong, R.; Yang, W.; Wu, P.; Hussain, M.; Wu, G.; Jiang, L. High content SiC nanowires reinforced Al composite with high strength and plasticity. Mater. Sci. Eng. A 2015, 630, 8-12. [CrossRef]

16. Dong, R.; Yang, W.; Yu, Z.; Wu, P.; Hussain, M.; Jiang, L.; Wu, G. Aging behavior of 6061Al matrix composite reinforced with high content $\mathrm{SiC}$ nanowires. J. Alloys Compd. 2015, 649, 1037-1042. [CrossRef]

17. Yang, W.; Dong, R.; Yu, Z.; Wu, P.; Hussain, M.; Wu, G. Strengthening behavior in high content SiC nanowires reinforced Al composite. Mater. Sci. Eng. A 2015, 648, 41-46. [CrossRef]

18. Dong, R.; Yang, W.; Wu, P.; Hussain, M.; Yu, Z.; Jiang, L.; Wu, G. Effect of reinforcement shape on the stress-strain behavior of aluminum reinforced with SiC nanowire. Mater. Des. 2015, 88, 1015-1020. [CrossRef]

19. Yang, W.; Chen, G.; Qiao, J.; Zhang, Q.; Dong, R.; Wu, G. Effect of Mg addition on the microstructure and mechanical properties of $\mathrm{SiC}$ nanowires reinforced 6061Al matrix composite. Mater. Sci. Eng. A 2017, 689, 189-194. [CrossRef]

20. Xin, L.; Yang, W.; Zhao, Q.; Dong, R.; Wu, P.; Xiu, Z.; Hussain, M.; Wu, G. Strengthening behavior in SiC nanowires reinforced pure Al composite. J. Alloys Compd. 2017, 695, 2406-2412. [CrossRef]

21. Shao, P.; Yang, W.; Zhang, Q.; Meng, Q.; Tan, X.; Xiu, Z.; Qiao, J.; Yu, Z.; Wu, G. Microstructure and tensile properties of $5083 \mathrm{Al}$ matrix composites reinforced with graphene oxide and graphene nanoplates prepared by pressure infiltration method. Compos. Part A Appl. Sci. Manuf. 2018, 109, 151-162. [CrossRef]

22. Xin, L.; Tian, X.; Yang, W.; Chen, G.; Qiao, J.; Hu, F.; Zhang, Q.; Wu, G. Enhanced stability of the Diamond/Al composites by $\mathrm{W}$ coatings prepared by the magnetron sputtering method. J. Alloys Compd. 2018, 763, 305-313. [CrossRef]

23. Ghandvar, H.; Idris, M.H.; Ahmad, N. Effect of hot extrusion on microstructural evolution and tensile properties of Al-15\%Mg2Si-xGd in-situ composites. J. Alloys Compd. 2018, 751, 370-390. [CrossRef]

24. Yang, W.; Zhao, Q.; Xin, L.; Qiao, J.; Zou, J.; Shao, P.; Yu, Z.; Zhang, Q.; Wu, G. Microstructure and mechanical properties of graphene nanoplates reinforced pure $\mathrm{Al}$ matrix composites prepared by pressure infiltration method. J. Alloys Compd. 2018, 732, 748-758. [CrossRef]

25. Chen, X.; Fu, D.; Teng, J.; Zhang, H. Hot deformation behavior and mechanism of hybrid aluminum-matrix composites reinforced with micro-SiC and nano-TiB 2 . J. Alloys Compd. 2018, 753, 566-575. [CrossRef]

26. Xin, L.; Yang, W.; Zhao, Q.; Dong, R.; Liang, X.; Xiu, Z.; Hussain, M.; Wu, G. Effect of extrusion treatment on the microstructure and mechanical behavior of $\mathrm{SiC}$ nanowires reinforced $\mathrm{Al}$ matrix composites. Mater. Sci. Eng. A 2017, 682, 38-44. [CrossRef]

27. Luan, B.F.; Hansen, N.; Godfrey, A.; Wu, G.H.; Liu, Q. High strength Al-Al2O3p composites: Optimization of extrusion parameters. Mater. Des. 2011, 32, 3810-3817. [CrossRef]

28. Tavighi, K.; Emamy, M.; Emami, A.R. Effects of extrusion temperature on the microstructure and tensile properties of Al-16 wt\% Al4Sr metal matrix composite. Mater. Des. 2013, 46, 598-604. [CrossRef]

29. Feng, Y.C.; Cao, G.J.; Fan, G.H.; Wang, L.P.; Geng, L.; Jiang, W.Y. Jiang, Influence of hot extrusion temperature on the microstructure and the mechanical properties of $(\mathrm{ABOw}+\mathrm{WO} 3 \mathrm{p}) / \mathrm{Al}$ hybrid composites. JOM 2013, 65, 593-598. [CrossRef]

30. Hong, S.H.; Chung, K.H.; Lee, C.H. Effects of hot extrusion parameters on the tensile properties and microstructures of SiCw-2124Al composite. Mater. Sci. Eng. A 1996, 206, 225-232. [CrossRef]

31. Wu, C.; Gao, T.; Sun, Q.; Liu, G.; Du, X.; Liu, X. A novel method of coating ex-situ SiC particles with in-situ $\mathrm{SiC}$ interlayer in Al-Si-C alloy. J. Alloys Compd. 2018, 754, 39-47. [CrossRef]

32. Zhang, C.; Yin, J.; Yao, D.; Zuo, K.; Xia, Y.; Liang, H.; Zeng, Y. Enhanced tensile properties of Al matrix composites reinforced with $\beta$-Si3N4 whiskers. Compos. Part A Appl. Sci. Manuf. 2017, 102, 145-153. [CrossRef]

33. Zhang, C.; Yao, D.; Yin, J.; Zuo, K.; Xia, Y.; Liang, H.; Zeng, Y.P. Effects of whisker surface modification on microstructures, mechanical and thermal properties of $\beta$-Si3N4 whiskers reinforced Al matrix composites. Mater. Des. 2018, 159, 117-126. [CrossRef] 
34. Shi, W.; Yuan, L.; Xu, F.; Zheng, Z.; Shan, D. Refining whisker size of 2024Al/Al18B4O33w composite through extrusion and its effects on the material's micro-structures and mechanical properties. Mater. Charact. 2018, 138, 98-106. [CrossRef]

35. Du, B.; Hong, C.; Zhang, X.; Wang, J.; Qu, Q. Preparation and mechanical behaviors of SiOC-modified carbon-bonded carbon fiber composite with in-situ growth of three-dimensional SiC nanowires. J. Eur. Ceram. Soc. 2018, 38, 2272-2278. [CrossRef]

36. Chen, J.; Ding, L.; Xin, L.; Zeng, F.; Chen, J. Thermochemistry and growth mechanism of SiC nanowires. J. Solid State Chem. 2017, 253, 282-286. [CrossRef]

37. Dong, R.; Yang, W.; Wu, P.; Hussain, M.; Xiu, Z.; Wu, G.; Wang, P. Microstructure characterization of SiC nanowires as reinforcements in composites. Mater. Charact. 2015, 103, 37-41. [CrossRef]

38. Ji, S. Generalized means as an approach for predicting Young's moduli of multiphase materials. Mater. Sci. Eng. A 2004, 366, 195-201. [CrossRef]

39. Chen, G.; Yang, W.; Xin, L.; Wang, P.; Liu, S.; Qiao, J.; Hu, F.; Zhang, Q.; Wu, G. Mechanical properties of Al matrix composite reinforced with diamond particles with $\mathrm{W}$ coatings prepared by the magnetron sputtering method. J. Alloys Compd. 2018, 735, 777-786. [CrossRef]

40. Shin, S.E.; Choi, H.J.; Hwang, J.Y.; Bae, D. Strengthening behavior of carbon/metal nanocomposites. Sci. Rep. 2015, 5, 16114. [CrossRef]

(C) 2019 by the authors. Licensee MDPI, Basel, Switzerland. This article is an open access article distributed under the terms and conditions of the Creative Commons Attribution (CC BY) license (http://creativecommons.org/licenses/by/4.0/). 